\title{
Flow Shear Induced Fluctuation Suppression in Finite Aspect Ratio Shaped Tokamak Plasma
}

\author{
T.S. Hahm \\ Princeton University, Princeton Plasma Physics Laboratory \\ P.O. Box 451, Princeton, NJ 08543 \\ K.H. Burrell \\ General Atomics \\ P.O. Box 85608, San Diego, CA92186-9784
}

\begin{abstract}
The suppression of turbulence by the $\mathbf{E} \times \mathbf{B}$ flow shear and parallel flow shear is studied in an arbitrary shape finite aspect ratio tokamak plasma using the two point nonlinear analysis previously utilized in a high aspect ratio tokamak plasma [Phys. Plasmas 1, 2940 (1994)]. The result shows that only the $\mathbf{E} \times \mathbf{B}$ flow shear is responsible for the suppression of flute-like fluctuations. This suppression occurs regardless of the plasma rotation direction and is, therefore, relevant for the VH mode plasma core as well as for the $\mathrm{H}$ mode plasma edge. Experimentally observed in-out asymmetry of fluctuation reduction behavior can be addressed in the context of flux expansion and magnetic field pitch variation on a given flux surface. The adverse effect of neutral particles on confinement improvement is also discussed in the context of the charge exchange induced parallel momentum damping.
\end{abstract}

${ }^{1}$ PACS numbers: $52.35 . \mathrm{Ra}, 52.35 . \mathrm{Qz}, 52.25 . \mathrm{Gj} .52 .55 . \mathrm{Fa}$

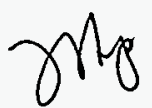

DSTRIBUTION OF THIS DOCUMENT IS UNLINITED 


\section{Introduction}

Since the high(H)-mode has first been discovered in the Axisymmetric Divertor Experiment $^{1}$ (ASDEX), there has been considerable experimental and theoretical progress in $\mathrm{H}$ mode physics. To date, fluctuation suppression by flow shear remains as one of the best hypothesis to explain not only the confinement improvement which occurs at the plasma edge at the $\mathrm{L}$ to $\mathrm{H}$ transition, ${ }^{2,3}$ but also radial broadening of the improved confinement zone into the plasma core which occurs during the VH (very high) mode phase. ${ }^{3}$ Since the most extensive $\mathrm{H}$ mode studies and VH mode studies accompanied by fluctuation measurements have been performed on strongly shaped tokamaks with divertor such as Doublet III-D ${ }^{3}$ (DIII-D), previous cylindrical theories ${ }^{4,5}$ and more recent theory ${ }^{6}$ in high aspect ratio near circular toroidal plasma cannot address all the important physics issues. In particular, for more meaningful quantitative comparison to experimental data, the flow shear induced fluctuation suppression criterion for non-circular shape, finite aspect ratio tokamak plasma is needed.

In this work, we extend the previous two-point nonlinear theory of flow shear induced fluctuation suppression in near circular, high aspect ratio toroidal plasma ${ }^{6}$ to arbitrary shape, finite aspect ratio toroidal plasma using orthogonal flux coordinates $(\psi, \theta, \phi)$. In particular, our formalism allows us to address the in-out asymmetry of fluctuation reduction behavior ${ }^{7}$ in the context of the shaping and finite aspect ratio associated effects such as flux expansion and poloidal variation of the local magnetic field pitch on a given flux surface.

Our results indicate that fluctuation suppression occurs when the decorrelation rate of the ambient turbulence $\Delta \omega_{T}$ is exceeded by the shearing rate $\omega_{s}$ due to the flow shear, given below:

$$
\omega_{s}^{2}=\left|\frac{\Delta \psi_{0}}{\Delta \phi} \frac{\partial^{2}}{\partial \psi^{2}} \Phi_{0}(\psi)\right|^{2}+\left|\frac{\Delta \psi_{0}}{\Delta \eta} \frac{\partial}{\partial \psi}\left(\frac{V_{\|}}{J B}\right)\right|^{2} /\left|1-\frac{\partial}{\partial \theta}\left(\frac{V_{\|}}{J B}\right) / \Delta \omega_{T}\right|^{2}
$$

where $\Delta \psi_{0} / R B_{\theta}, R \Delta \phi$, and $J B \Delta \eta$ are the correlation lengths of the ambient turbulence in the radial, toroidal, and parallel (to $\mathrm{B}$ ) directions respectively, and $J \equiv(\nabla \psi \times \nabla \phi \cdot \nabla \theta)^{-1}$ is the Jacobian. From this we conclude that:

(i.) For flute-like fluctuations with $\Delta \eta \gg 1$, the shearing rate is determined by $\mathbf{E} \times \mathbf{B}$ 


\section{DISCLAIMER}

This report was prepared as an account of work sponsored by an agency of the United States Government. Neither the United States Government nor any agency thereof, nor any of their employees, make any warranty, express or implied, or assumes any legal liability or responsibility for the accuracy, completeness, or usefulness of any information, apparatus, product, or process disclosed, or represents that its use would not infringe privately owned rights. Reference herein to any specific commercial product, process, or service by trade name, trademark, manufacturer, or otherwise does not necessarily constitute or imply its endorsement, recommendation, or favoring by the United States Government or any agency thereof. The views and opinions of authors expressed herein do not necessarily state or reflect those of the United States Government or any agency thereof. 


\section{DISCLAIMER}

Portions of this document may be illegible in electronic image products. Images are produced from the best available original document. 
flow only. Therefore, a simple formula $\omega_{s}^{\ddot{*}}=\left|\left(\Delta \psi_{0} / \Delta \phi\right) \partial^{2} \Phi_{0}(\psi) / \partial \psi\right|$ is applicable not only at the edge where the poloidal rotation is appreciable but also at the core where plasma rotates mainly in toroidal direction. For fixed $\Delta \phi$ and $\Delta r_{0}$, the shearing rate is higher at the large major radius side due to flux expansion $\left(\Delta \psi_{0}=R B_{\theta} \Delta r_{0}\right)$.

(ii.) For ballooning-like fluctuations $(\Delta \eta \sim \pi), \partial\left(V_{\|} / J B\right) / \partial \psi$ term also contributes to the shearing rate. For fixed $\Delta \eta$, this term is also large at the large major radius side due to poloidal variation of the local magnetic field pitch.

(iii.) If the neoclassical theory expression for $V_{\|}$is used, the charge-exchange induced parallel momentum damping is predicted to reduce the shearing rate. This qualitatively agrees with the experimental observation that the presence of neutral particles has adverse effects on confinement improvement. ${ }^{8}$

The remainder of this paper is organized as follows. In Sec. II, the two-point correlation function evolution equation in flux coordinates is derived and analyzed. Then the general criterion for flow shear suppression of fluctuation is presented. In Sec. III, the $\mathbf{E} \times \mathbf{B}$ flow shear suppression criterion for flute-like fluctuation is discussed in detail in relation to experimental observations. Finally, the role of parallel flow and neutral particles is discussed in Sec. IV.

\section{Two-Point Correlation Evolution in Flux Coordinates}

Following the previous work, ${ }^{4-6}$ we start from a one-field fluid model in which the fluctuating field $\delta H$ is convected by the equilibrium flow $V_{0}=V_{E}+V_{\|} b$, and the fluctuating $E \times B$ flow $\tilde{V}_{E}$,

$$
\left(\partial / \partial t+V_{0} \cdot \nabla+\tilde{V}_{E} \cdot \nabla\right) \delta H=S
$$

where $V_{E}=E_{\tau}^{(0)} \times B / B^{2}, \tilde{V}_{E}=B \times \nabla \delta \Phi / B^{2}$, and $S$ is the driving source of the turbulence. Linear dissipation and subdominant nonlinearities other than $E \times B$ nonlinearity are ignored for simplicity. In strongly shaped tokamaks, a natural representation of the small scale (high mode number) fluctuating field is provided by the ballooning formalism in flux coordinates, 


$$
\delta H(\psi, \theta, \phi)=\sum_{n} e^{i n \phi} \sum_{m} e^{-i m \theta} \int d \eta e^{i S} \delta H_{n}(\eta, \psi)
$$

where $\phi$ and $\theta$ are the toroidal angle and poloidal angle respectively, $\eta$ is the ballooning coordinate, $\psi$ is the poloidal flux, and $S \equiv n\left\{\phi-\int^{\theta} d \theta \nu+\int^{\psi} d \psi k(\psi)\right\}$ is the eikonal which describes the fast variation of $\delta H$ across $B$. Note that $B \cdot \nabla S=0$ is satisfied. In this coordinate system, $B=\nabla \phi \times \nabla \psi+I(\psi) \nabla \phi, B_{\phi}=I(\psi) / R$, and $B_{\theta}=|\nabla \psi| / R$.

The Jacobian is given by $J \equiv(\nabla \psi \times \nabla \phi \cdot \nabla \theta)^{-1}$, and $\nu \equiv I J / R^{2}$ is the local pitch of magnetic field which can vary on a flux surface. $q(\psi) \equiv(1 / 2 \pi) \oint d \theta \nu$ is the magnetic safety factor. Since

$$
\nabla=e_{\psi} R B_{\theta} \frac{\partial}{\partial \psi}+e_{\theta} \frac{1}{J B_{\theta}} \frac{\partial}{\partial \theta}+e_{\phi} \frac{1}{R} \frac{\partial}{\partial \phi}
$$

we have

$$
V_{0} \cdot \nabla \delta H=\left\{-\frac{\partial \Phi_{0}(\psi)}{\partial \psi} \frac{\partial}{\partial \phi}+\frac{V_{\|}}{J B} \frac{\partial}{\partial \eta}\right\} \delta H
$$

In this work, $\Phi_{0}$ is assumed to be a flux function, meanwhile $V_{\|} / J B$ is allowed to vary on a given flux surface in general. The expression for the $E \times B$ nonlinear term in flux coordinate is given by Frieman and Chen.. ${ }^{9}$ The two-point correlation evolution equation is then derived following the standard procedure ${ }^{10}$ of symmetrization with respect to $\left(\psi_{1}, \phi_{1}, \eta_{1}\right)$ and $\left(\psi_{2}, \phi_{2}, \eta_{2}\right)$ followed by ensemble average,

$$
\left\{\frac{\partial}{\partial t}+\psi_{-}\left(\Omega_{\perp \psi}^{\prime} \frac{\partial}{\partial \phi_{-}}+\Omega_{\| \psi}^{\prime} \frac{\partial}{\partial \eta_{-}}\right)+\eta_{-} \Omega_{\| \theta}^{\prime} \frac{\partial}{\partial \eta_{-}}-D_{-}^{\text {eff }} \frac{\partial^{2}}{\partial \phi_{-}^{2}}\right\}<\delta H(1) \delta H(2)>=S_{2} .
$$

Here, the radial shear of the angular rotation frequency in perpendicular and parallel directions is given by

$$
\Omega_{\perp \psi}^{\prime} \equiv-\frac{\partial^{2}}{\partial \psi^{2}} \Phi_{0}(\psi),
$$

and

$$
\Omega_{\| \psi}^{\prime} \equiv \frac{\partial}{\partial \psi}\left(\frac{V_{\|}}{J B}\right)
$$


The poloidal variation of the parallel angular frëquency is given by

$$
\Omega_{\| \theta}^{\prime} \equiv \frac{\partial}{\partial \theta}\left(\frac{V_{\|}}{J B}\right)
$$

In Eq. (4), $S_{2}$ is the source term for the two-point correlation function and the $E \times B$ nonlinearity is approximated as a turbulent diffusion along the perpendicular direction. ${ }^{11}$ At small separation, the relative diffusion $D_{-}^{\text {eff }}$ has the following asymptotic form, .

$$
D_{-}^{\mathrm{eff}}=2 D^{\mathrm{eff}}\left\{\left(\frac{\psi_{-}}{\Delta \psi_{0}}\right)^{2}+\left(\frac{\eta_{-}}{\Delta \eta}\right)^{2}+\left(\frac{\phi_{-}}{\Delta \phi}\right)^{2}\right\}
$$

where $D^{\text {eff }}=\Delta \omega_{T} \Delta \phi^{2} / 4$ is proportional to the diffusion coefficient at large separation. The decorrelation dynamics due to the coupling of the flow shear and turbulent diffusion can be studied by taking various moments of the left hand side (lhs) of Eq. (4).

$$
\begin{gathered}
\partial_{t}<\psi_{-}^{2}>=0 \\
\partial_{t}<\phi_{-}^{2}>=4 D_{\text {eff }}\left\{\frac{\left\langle\eta_{-}^{2}>\right.}{\Delta \eta^{2}}+\frac{<\phi_{-}^{2}>}{\Delta \phi^{2}}+\frac{<\psi_{-}^{2}>}{\Delta \psi_{0}^{2}}\right\}+2 \Omega_{\perp \psi}^{\prime}<\psi_{-} \phi_{-}> \\
\partial_{t}<\eta_{-}^{2}>=2 \Omega_{\| \psi}^{\prime}<\psi_{-} \eta_{-}>+2 \Omega_{\| \theta}^{\prime}<\eta_{-}^{2}> \\
\partial_{t}<\psi_{-} \phi_{-}>=\Omega_{\perp \psi}^{\prime}<\psi_{-}^{2}> \\
\partial_{t}<\psi_{-} \eta_{-}>=\Omega_{\| \psi}^{\prime}<\psi_{-}^{2}>+\Omega_{\| \theta}^{\prime}<\psi_{-} \eta_{-}>
\end{gathered}
$$

and

$$
\partial_{t}<\eta_{-} \phi_{-}>=\Omega_{\perp \psi}^{\prime}<\psi_{-} \eta_{-}>+\Omega_{\| \psi}^{\prime}<\psi_{-} \phi_{-}>+\Omega_{\| \theta}^{\prime}<\eta_{-} \phi_{-}>
$$

Here,

$$
<A\left(\eta_{-}, \phi_{-}, \psi_{-}\right)>\equiv \int d \eta_{-}^{\prime} d \phi_{-}^{\prime} d \psi_{-}^{\prime} G\left(\eta_{-}, \phi_{-}, \psi_{-} \mid \eta_{-}^{\prime}, \phi_{-}^{\prime}, \psi_{-}^{\prime}\right) A\left(\eta_{-}^{\prime}, \phi_{-}^{\prime}, \psi_{-}^{\prime}\right),
$$

and $G$ is the two point Green's function for the lhs of Eq. (4). 
Integration of Eqs. (9) through (14) yields a solution which has the following asymptotic form for $\Delta \omega_{T} t>1$

$$
\begin{aligned}
\frac{<\phi_{-}^{2}>(t)}{\Delta \phi^{2}} & =\left[\frac{\psi_{-}^{2}}{\Delta \psi_{0}^{2}}\left\{1+\left(\frac{\Omega_{\perp \psi}^{\prime}}{\Delta \phi} \frac{\Delta \psi_{0}}{\Delta \omega_{T}}\right)^{2}+\left(\frac{\Omega_{\| \psi}^{\prime} \Delta \psi_{0}}{\Delta \eta \Delta \omega_{T}}\right)^{2}\left(1-\frac{\Omega_{\| \theta}^{\prime}}{\Delta \omega_{T}}\right)^{2}\right\}+\frac{1}{\Delta \phi^{2}}\left(\phi_{-}+\frac{\Omega_{\perp \psi}^{\prime}}{\Delta \Omega_{T}} \psi_{-}\right)^{2}\right. \\
& \left.+\frac{1}{\left(1-2 \Omega_{\| \theta}^{\prime} / \Delta \omega_{T}\right) \Delta \eta^{2}}\left(\eta_{-}+\frac{\Omega_{\| \psi}^{\prime}}{\Delta \omega_{T}-\Omega_{\| \theta}^{\prime}} \psi_{-}\right)^{2}\right] e^{\Delta \omega_{T} t}
\end{aligned}
$$

Here, $\Omega_{\| \theta}^{\prime} \ll \Delta \omega_{T}$, implying weak poloidal variation of the parallel angular rotation is assumed. Equation(15) yields the eddy lifetime and is a function of the initial separation between two nearby points,

$$
\tau_{\text {eddy }} \simeq \Delta \omega_{T}^{-1} \ln \left([\cdots]^{-1}\right),
$$

where $[\cdots]$ is the expression multiplying $e^{\Delta \omega_{T} t}$ on the RHS of Eq. (15). We recall that Eq. (8) implies $[\cdots]<1$. The radial correlation length $\Delta r_{t} \equiv \Delta \psi / R B_{\theta}$, is reduced by the flow shear relative to its value $\Delta r_{0} \equiv \Delta \psi_{0} / R B_{\theta}$, determined by ambient turbulence alone:

$$
\left(\frac{\Delta \psi_{0}}{\Delta \psi}\right)^{2}=1+\frac{\omega_{s}^{2}}{\Delta \omega_{T}^{2}}
$$

Therefore, we expect that fluctuation suppression occurs when the decorrelation rate of the ambient turbulence $\Delta \omega_{T}$ is exceeded by the shearing rate, $\omega_{s}$ :

$$
\omega_{s}^{2}=\left(\frac{\Delta \psi_{0}}{\Delta \phi}\right)^{2}\left|\frac{\partial^{2}}{\partial \psi^{2}} \Phi_{0}(\psi)\right|^{2}+\left(\frac{\Delta \psi_{0}}{\Delta \eta}\right)^{2}\left|\frac{\partial}{\partial \psi}\left(\frac{V_{\|}}{J B}\right)\right|^{2} /\left|1-\frac{\partial}{\partial \theta}\left(\frac{V_{\|}}{J B}\right) / \Delta \omega_{T}\right|^{2}
$$

\section{III. $E \times B$ Flow Shear Suppression of Flute-like Fluctuations}

For flute-like fluctuations with $\Delta \eta \gg 1$, only the first term $(E \times B$ flow shear) on the rhs of Eq. (18) is important. It is important to note that this is true regardless of the plasma rotation direction. In particular, even at core region of VH mode where plasma rotates in the toroidal direction, it is $E \times B$ flow shear not the parallel flow shear which contributes to the fluctuation suppression. We note that a heuristic approach based only upon modification of the linear propagator ${ }^{12}$ has reached a conclusion different from our two-point nonlinear theory. Despite its simplicity, the first term on the rhs of Eq. (18) still contains quantities 
which are not directly measured experimentally to date. This fact leads to a number of different possibilities in discussing the implications of Eq. (18) for the in-out asymmetry of fluctuation reduction behavior. ${ }^{7}$ At present, there exists little experimental evidence to determine which version is better.

(i.) If the ambient flute-like turbulence is such that $\Delta \psi_{0}$, and $\Delta \phi$ are constant on a given flux surface, the $E \times B$ shearing rate

$$
\omega_{s E} \equiv\left(\frac{\Delta \psi_{0}}{\Delta \phi}\right)\left|\frac{\partial^{2}}{\partial \psi^{2}} \Phi_{0}(\psi)\right|,
$$

is also a constant on a given flux surface. This assumption of constant $\Delta \psi_{0}$ and $\Delta \phi$ is plausible from a purely theoretical point of view (in particular, if the linear eigenmode structure is maintained in nonlinear regime ${ }^{13}$ ) because the radial width of the linear eigenmode is determined by the spatial variation rate of flux functions in flux unit, for example, magnetic shear, radial variation of the diamagnetic drift frequency, or the distance between neighboring rational surfaces.

(ii.) Another possibility comes from more practical considerations, i.e., the constraints set by the experimental arrangements. Since the density fluctuation measurement via microwave scattering is performed for a number of specific values of $k_{\theta}$ which is determined by the scattering geometry, and what is measured directly from diagnostics such as reflectometer, or beam emission spectroscopy is the radial correlation length $\Delta r$, rather than $\Delta \psi$, it is more useful to write $\omega_{s E}$ in terms of $\Delta \Theta$ and $\Delta r$. Since flute-like fluctuations align along $B$, we have $\Delta \phi=\nu \Delta \Theta$ where $\Delta \Theta$ is the poloidal correlation angle. Then, $E \times B$ shearing rate can be written as

$$
\omega_{s E}=\left(\frac{R B_{\theta} \Delta r_{0}}{\nu \Delta \Theta}\right)\left|\frac{\partial^{2}}{\partial \psi^{2}} \Phi_{0}(\psi)\right| .
$$

Then, for fixed $\Delta \Theta$ and $\Delta r_{0}, \omega_{s E}$ varies like $R B_{\theta} / \nu \approx\left(R B_{\theta}\right)^{2} / r B_{\phi} \infty R^{2}$, and the shearing rate is significantly higher at the large major radius side. We recall that the origin of the major radius dependence is flux expansion $\left(\Delta \psi=R B_{\theta} \Delta r\right)$ and the variation of the local magnetic pitch $\nu$. Future density fluctuation measurements at the 
small major radius side ${ }^{14}$ can shed more light into understanding the in-out asymmetry . of fluctuation reduction behavior. It is remarkable that Eq. (19) (with $\nu \simeq r B_{\phi} / R B_{\theta}$ and $\left.\Delta \theta=1 / \vec{k}_{\theta} r_{0}\right)$ has been deduced earlier ${ }^{2}$ from the previous cylindrical theory ${ }^{4}$ by a proper generalization of the radial derivative to flux coordinates and requiring $\Phi_{0}$ to be a flux function. In Ref. 2 , an approximation

$$
\left|\frac{\partial E_{r}}{\partial r}\right|^{2}=\left|R B_{\theta} \frac{\partial}{\partial \psi} R B_{\theta} \frac{\partial \Phi_{0}}{\partial \psi}\right|^{2} \approx\left(R B_{\theta}\right)^{2}\left|\frac{\partial^{2}}{\partial \psi^{2}} \Phi_{0}\right|^{2}
$$

has been made to deduce Eq. (19) from the previous cylindrical result. Although this approximation is justified at the edge of $\mathrm{H}$ mode plasma (the topic in Ref. 2), the radial variation of $R B_{\theta}$ must be taken into account for fluctuation suppression at the core which occurs at $\mathrm{H}$ to $\mathrm{VH}$ transition. Our toroidal theory shows that $\left|R B_{\theta}\left(\partial^{2} / \partial \psi^{2}\right) \Phi_{0}\right|$ rather than $\left|(\partial / \partial \psi) R B_{\theta}\left(\partial \Phi_{0} / \partial \psi\right)\right|$ is the correct expression even in the absence of an additional assumption of sharp $E_{r}$ variation. Another subtle difference is that, while Ref. 2 implies that $R B_{\theta} / \nu$ on the rhs of Eq. (19) should be evaluated after the fluctuation suppression, the present toroidal theory indicates that $R B_{\theta} / \nu$ should be the value before the suppression. Although this difference is not significant in most cases, it may lead to quantitative difference in the elongation-ramp experiment ${ }^{15}$ or the current-ramp experiment. ${ }^{16}$

\section{Role of Parallel Flow Shear and Neutral Particles}

For ballooning-like fluctuations with $\Delta \eta \sim \pi$, the second term on the RHS of Eq. (18) is not negligible. $\partial\left(V_{\|} / J B\right) / \partial \theta$ term in denominator produces an up-down asymmetry of the fluctuation suppression criterion and vanishes at the midplane. To study the poloidal variation of $\partial\left(V_{\|} / J B\right) / \partial \theta$, we recall that $V_{\|}$cannot be arbitrary, and must satisfy the constraint, $\nabla \cdot(n V) \simeq 0$. If the density $n$ is assumed to be a flux function, the parallel flow can be written $\operatorname{as}^{17} V_{\|}=K(\psi) B+\omega(\psi) I(\psi) / B$. Then using $\nu=I J / R^{2}$, we obtain

$$
\frac{V_{\|}}{J B}=\frac{K(\psi) I(\psi)}{\nu R^{2}}+\frac{\omega(\psi)}{\nu}\left(\frac{B_{\phi}}{B}\right)^{2}
$$


Typically the second term on the rhs dominates at tokamak core where plasma rotates mainly in toroidal direction. Meanwhile the first term tends to be significant at the edge where the poloidal rotation is appreciable. In DIII-D, the local magnetic pitch $\nu$ is a lot smaller at the larger major radius side making the shearing rate $\omega_{s}$ larger compared to that at the smaller major radius side. The variation of $1 / \nu R^{2}$ is relatively minor. The poloidal dependence of $V_{\|} / J B$ can be more clearly manifested in the following expression,

$$
\frac{V_{\|}}{J B}=\frac{<V_{\|} B>}{J B^{2}}+K(\psi)\left(\frac{1}{J}-\frac{<B^{2}>}{J B^{2}}\right),
$$

where the bracket indicates the flux-surface average value.

It is well-know that wall conditioning is a key experimental requirement for obtaining enhanced confinement regime such as H-mode. ${ }^{8}$ In this section, we show that the experimentally observed adverse effects of neutrals are qualitatively consistent with the flow shear suppression scenario. Although it is not entirely clear yet how accurately the neoclassical theory predicts plasma flow at the tokamak edge ${ }^{19}$ we discuss the role of charge-exchange induced drag on parallel flow in modifying the shear suppression criterion in the context of the neoclassical theory prediction.

Neoclassical theory predicts that, at steady state, ${ }^{20}$

$$
K(\psi)=\frac{-\nu_{c x}}{\nu_{\|}+\nu_{c x}} \frac{I(\psi) \omega(\psi)}{\left\langle B^{2}\right\rangle},
$$

where $\nu_{c x}=n_{N}\langle\sigma v\rangle_{c x}$ is the charge exchange rate, and $\nu_{\|}$is the magnetic pumping rate. From Eq. (22), we obtain

$$
V_{\|}=\omega(\psi) I(\psi)\left(\frac{1}{B}-\frac{B}{<B^{2}>} \frac{\nu_{c x}}{\nu_{\|}+\nu_{c x}}\right)
$$

which clearly shows that the steady state value of $V_{\|}$is reduced by the charge exchange induced drag. Consequently, the presence of neutrals makes the flow shear suppression of fluctuation less effective. Furthermore, there is theoretical possibility that ionization process can enhance the fluctuation level of dissipative drift wave turbulence. ${ }^{21.22}$ This effect can also enhance ambient turbulence decorrelation rate $\Delta \omega_{T}$, making the transition to enhanced confinement regime harder. 
Finally, in the absence of experimental indications on the parallel correlation angle $\Delta \eta$, it will be illuminating to contrast the two limiting cases, $\Delta \eta \rightarrow \infty$ and $\Delta \eta \simeq \pi$.

\section{Acknowledgments}

The authors would like to thank F.L. Hinton, Y.B. Kim, M.S. Chu, L.L. Lao, and G.M. Staebler for useful discussions. They are also grateful to W.M. Tang and V. Chan for encouragement. This work was supported by U.S. Department of Energy Contract No. DE-AC02-76-CHO-3073. 


\section{References}

${ }^{1}$ F. Wagner, G. Becker, K. Behringer, D. Campbell, A. Eberhagen, W. Engelhardt, G. Fussmann, O. Gehre, J. Gerhardt, G. v. Vierke, G. Haas, M. Huang, F. Karger, M. Keilhacker, O. Kluber, M. Kornherr, K. Lackner, G. Lisitano, G.G. Lister, H.M. Mayer, D. Meisel, E.R. Muller, H. Murmann, H. Niedermeyer, W. Poschenrieder, H. Rapp, H. Rohr, F. Schneider, G. Siller, E. Speth, A. Stbler, K. H. Steuer, G. Venus, O. Vollmer, and Z. Yu, Phys. Rev. Lett. 49, 1408 (1982).

${ }^{2}$ K.H. Burrell, T.N. Carlstrom, E.J. Doyle, D. Finkenthal, P. Gohil, R.J. Groebner, D.L. Hillis, J. Kim, H. Matsumoto, R.A. Moyer, T.H. Osborne, C.L. Rettig, W.A. Peebles, T.L. Rhodes, H. St. John, R.D. Stambaugh, M.R. Wade, and J.G. Watkins, Plasma Phys. Control. Fus. 34, 1859 (1992).

${ }^{3}$ K.H. Burrell, E.J. Doyle, P. Gohil, R.J. Groebner, J.Kim, R.J La Haye, L.L. Lao, R.A. Moyer, T.H. Osborne, W.A. Peebles, C.L. Rettig, T.H. Rhodes, and D.M. Thomas, Phys. Plasmas, 1, 1536 (1994).

${ }^{4}$ H. Biglari, P.H. Diamond, and P.W. Terry, Phys. Fluids B 2, 1 (1990).

${ }^{5}$ K.C. Shaing, E.C. Crume, Jr., and W.A. Houlberg, Phys. Fluids B 2, 1492 (1990).

${ }^{6}$ T.S. Hahm, Phys. Plasmas 1, 2940 (1994).

${ }^{7}$ T.L. Rhodes, R.J. Taylor, E.J. Doyle, N.C. Luhmann, Jr., and W.A. Peebles, Nucl. Fusion, 33, 1787 (1993).

${ }^{8}$ F. Wagner, Plasma Phys. Controlled Fus. 36, A319 (1994).

${ }^{9}$ E.A. Frieman and L. Chen, Phys. Fluids 25, 502 (1982).

${ }^{10}$ T. H. Dupree, Phys. Fluids 15, 334 (1972).

${ }^{11}$ P.W. Terry and P.H. Diamond, Phys. Fluids 28, 1419 (1985).

${ }^{12}$ K.C. Shaing, Phys. Plasmas 1, 219 (1994). 
${ }^{13}$ T.S. Hahm and P.H. Diamond, Phys. Fluids 30, 133 (1987).

${ }^{14}$ C.L. Rettig and T.L. Rhodes, Private communications (1994).

${ }^{15}$ L.L. Lao, J.R. Ferron, T.S. Taylor, K.H. Burrell, V.S. Chan, M.S. Chu, J.C. Deboo, E.J. Doyle, C.M. Greenfield, R.J. Groebner, R.A. James, E.A. Lazarus, T.H. Osborne, H. St. John, E.J. Strait, S.J. Thompson, A.D. Turnbull, D. Wroblewski, H. Zohm, and the DIII-D Team, Phys. Rev. Lett. 70, 3435 (1993).

${ }^{16}$ K. Toi, K. Kawahata, S. Morita, T. Watari, R. Kumazawa, K. Ida, A. Ando, Y. Oka, M. Sakamoto, Y. hamada, K. Adati, R. Ando, T. Aoki, S. Kidekuma, S. Krokura, O. Kaneko, A. Karita, T. Kawamoto, Y. Kawasumi, T. Kuroda, K. Masai, K. Narihara, Y. Ogawa, K. Ohkubo, S. Okajima, T. Osaki, M. Sasao, K.N. Sato, T. Seki, F. Shimpo, H. Takahashi, S. Tanahashi, Y. Taniguchi, and T. Tsuzuki, Phys. Rev. Lett. 64, 1895 (1990).

${ }^{17}$ S.P. Hirshman and D. J. Sigmar, Nucl. Fusion 21, 1079 (1981).

${ }^{18}$ T.H. Osborne, K.H. Burrell, T.N. Carlstrom, M.S. Chu, J.C. DeBoo, E.J. Doyle, P. Gohil, C.M. Greenfield, R.J. Groebner, G.L. Jackson, Y.B. Kim, S. Konoshima, R.J. LaHaye, L.L. Lao, S.I. Lippman, C.L. Rettig, D. Stambaugh, G.M. Staebler, H. St. John, E.J. Strait, T.S. Taylor, S.J. Thompson, A.D. Turnbull, J. Winter, and D. Wroblewski, Confinement and Stability of VH-mode Discharges in the DIII-D Tokamak, submitted to Nucl. Fusion (1992).

${ }^{19}$ J. Kim, K.H. Burrell, P.Gohil, R.J. Groebner, Y.B. Kim, H.E. St. John, R.P. Seraydarian, and M.E. Wade, Phys. Rev. Lett. 72, 2199 (1994).

${ }^{20}$ F.L. Hinton, Private Communications (1994).

${ }^{21}$ A.S. Ware, P.H. Diamond, H. Biglari, B.A. Carreras, L.A. Charlton, J.-N. Leboeuf, and A.J. Wootton, Phys. Fluids B 4, 877 (1992).

${ }^{22}$ M.A. Beer and T.S. Hahm, Phys. Fluids B 4, 2567 (1992). 


\section{EXTERNAL DISTRIBUTION IN ADDITION TO UC-420}

Dr. F. Paoloni, Univ. of Wollongong, AUSTRALIA

Prof. R.C. Cross, Univ. of Sydney, AUSTRALIA

Plasma Research Lab., Australian Nat. Univ., AUSTRALIA

Prof. I.R. Jones, Flinders Univ, AUSTRALIA

Prof. F. Cap, Inst. for Theoretical Physics, AUSTRIA

Prof. M. Heindler, Institut für Theoretische Physik, AUSTRIA

Prof. M. Goossens, Astronomisch Instituut, BELGIUM

Ecole Royale Militaire, Lab. de Phy. Plasmas, BELGIUM

Commission-European, DG. XII-Fusion Prog., BELGIUM

Prot. R. Bouciqué, Rijksuniversiteit Gent, BELGIUM

Dr. P.H. Sakanaka, Instituto Fisica, BRAZIL

Prof. Dr. 1.C. Nascimento, Instituto Fisica, Sao Paulo, BRAZIL Instituto Nacional De Pesquisas Espaciais-INPE, BRAZIL

Documents Office, Atomic Energy of Canada Ltd., CANADA

Ms. M. Morin, CCFMTtokamak de Varennes, CANADA

Dr. M.P. Bachynski, MPB Technologies, Inc., CANADA

Dr. H.M. Skarsgard, Univ. of Saskatchewan, CANADA

Prof. J. Teichmann, Univ. of Montreal, CANADA

Prof. S.R. Sreenivasan, Univ. of Calgary, CANADA

Prof. T.W. Johnston, INRS-Energie, CANADA

Dr. A. Bolton, Centre canadien de fusion magnétique, CANADA

Dr. C.R. James,, Univ. of Alberta, CANADA

Dr. P. Lukác, Komenského Universzita, CZECHO-SLOVAKIA

The Librarian, Culham Laboratory, ENGLAND

Library, R61, Rutherford Appleton Laboratory, ENGLAND

Mrs. S.A. Hutchinson, JET Library, ENGLAND

Dr. S.C. Sharma, Univ. of South Pacific, FIJI ISLANDS

P. Măhönen, Univ. of Helsinki, FINLAND

Prof. M.N. Bussac, Ecole Polytechnique, FRANCE

C. Mouttet, Lab. de Physique des Milieux lonisés, FRANCE

J. Radet, CEN/CADARACHE - Bat 506, FRANCE

Prof. E. Economou, Univ. of Crete, GREECE

Ms. C. Rinni, Univ. of loannina, GREECE

Preprint Library, Hungarian Academy of Sci., HUNGARY

Dr. B. DasGupta, Saha Inst. of Nuclear Physics, INDIA

Dr. P. Kaw, Inst. for Plasma Research, INDIA

Dr. P. Rosenau, Israel inst. of Technology, ISRAEL

Librarian, Intemational Center for Theo Physics, ITALY

Miss C. De Palo, Associazione EURATOM-ENEA, ITALY

Dr. G. Grosso, Istituto di Fisica del Plasma, ITALY

Prof. G. Rostangni, istituto Gas lonizzati Del Cnr, ITALY
Dr. H. Yamato, Toshiba Res \& Devel Center, JAPAN

Prof. I. Kawakami, Hiroshima Univ., JAPAN

Prof. K. Nishikawa, Hiroshima Univ., JAPAN

Librarian, Naka Fusion Research Establishment, JAERI, JAPAN

Director, Japan Atomic Energy Research Inst., JAPAN

Prof. S. Itoh, Kyushu Univ., JAPAN

Research Info. Ctr., National Instit. for Fusion Science, JAPAN

Prof. S. Tanaka, Kyoto Univ., JAPAN

Library, Kyoto Univ., JAPAN

Prof. N. Inoue, Univ. of Tokyo, JAPAN

Secretary, Plasma Section, Electrotechnical Lab., JAPAN

Dr. O. Mitarai, Kumamoto Inst. of Technology, JAPAN

Dr. G.S. Lee, Korea Basic Sci. Ctr., KOREA

J. Hyeon-Sook, Korea Atomic Energy Research Inst., KOREA

D.I. Choi, The Korea Adv. Inst. of Sci. \& Tech., KOREA

Prof. B.S. Liley, Univ. of Waikato, NEW ZEALAND

Inst of Physics, Chinese Acad Sci PEOPLE'S REP. OF CHINA

Library, Inst. of Plasma Physics, PEOPLE'S REP. OF CHINA

Tsinghua Univ. Library, PEOPLE'S REPUBLIC OF CHINA

Z. Li, S.W. Inst Physics, PEOPLE'S REPUBLIC OF CHINA

Prof. J.A.C. Cabral, Instituto Superior Tecnico, PORTUGAL

Prof. M.A. Hellberg, Univ. of Natal, S. AFRICA

Prof. D.E. Kim, Pohang Inst. of Sci. \& Tech., SO. KOREA

Prof. C.I.E.M.A.T, Fusion Division Library, SPAIN

Dr. L. Stenflo, Univ. of UMEA, SWEDEN

Library, Royal inst. of Technology, SWEDEN

Prof. H. Wilhelmson, Chalmers Univ. of Tech., SWEDEN

Centre Phys. Des Plasmas, Ecole Polytech, SWITZERLAND

Bibliotheek, Inst. Voor Plasma-Fysica, THE NETHERLANDS

Asst. Prof. Dr. S. Cakir, Middle East Tech. Univ., TURKEY

Dr. V.A. Glukhikh,Sci. Res. Inst. Electrophys.I Apparatus, USSR

Dr. D.D. Ryutov, Siberian Branch of Academy of Sci., USSR

Dr. G.A. Eliseev, I.V. Kurchatov Inst., USSR

Librarian, The Ukr.SSR Academy of Sciences, USSR

Dr. LM. Kovizhnykh, Inst. of General Physias, USSR

Kemforschungsanlage GmbH, Zentralbibliothek, W. GERMANY

Bibliothek, Inst. Für Plasmaforschung, W. GERMANY

Prof. K. Schindler, Ruhr-Universitát Bochum, W. GERMANY

Dr. F. Wagner, (ASDEX), Max-Planck-Institut, W. GERMANY

Librarian, Max-Planck-Institut, W. GERMANY 